\title{
Perspectives of Orthopedic Surgeons on the Clinical Use of Bioprinted Cartilage: Qualitative Study
}

Àngels Salvador Verges ${ }^{1}, \mathrm{MD}$; Luis Fernández-Luque ${ }^{2}, \mathrm{PhD}$; Meltem Yildirim ${ }^{3}, \mathrm{PhD}$; Bertran Salvador-Mata ${ }^{4}$, BTech; $^{2}$ Francesc Garcia Cuyàs ${ }^{5}, \mathrm{MD}, \mathrm{PhD}$

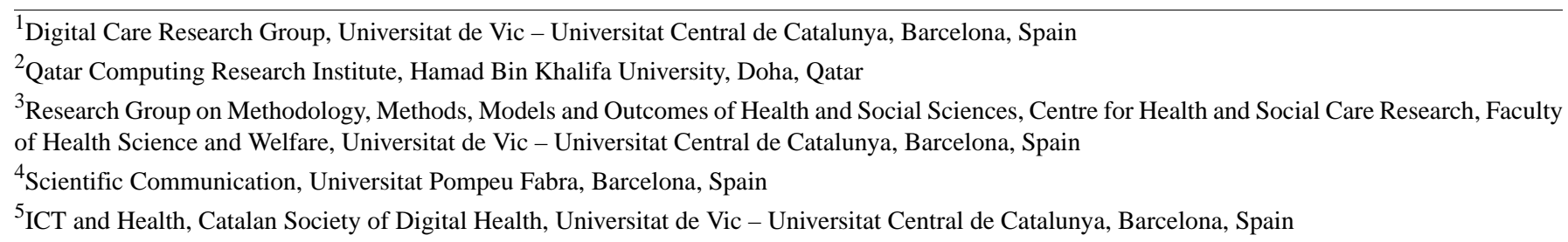

Corresponding Author:

Àngels Salvador Verges, MD

Digital Care Research Group

Universitat de Vic - Universitat Central de Catalunya

11, Magi Casanovas

Barcelona, 08870

Spain

Phone: 34630887995

Email: angels.salvador@uvic.cat

\begin{abstract}
Background: Over the past 60 years, no technique used for treating cartilage disorders has been completely successful. Bioprinting provides a highly anticipated, novel alternative solution to this problem. However, identifying barriers to this new technology is crucial in order to overcome them when bioprinting reaches the implementation stage. This kind of research has been declared essential because clinical efficacy and safety studies alone do not always lead to successful implementation.

Objective: This qualitative study aimed to explore the stance of orthopedic surgeons on the use of bioprinted cartilage grafts for cartilaginous lesions. The study sought to summarize and classify the barriers and facilitators of this technique and to identify the key factors for successful implementation of bioprinted cartilage in routine clinical practice.

Methods: A qualitative thematic analysis method was used to evaluate data obtained from semistructured interviews and from focus groups. Data were collected between June 2017 and February 2018. Interviews focused on the collection of expert opinions on bioprinted cartilage.

Results: The perceived barriers to the adoption of this technology were (1) awareness of a lack of information on the status and possibilities of this technology, (2) uncertainty regarding compliance with current health care regulations and policies, and (3) demands for clinical evidence. The facilitators were (1) lack of surgical alternatives, (2) the perception that research is the basis of the current health system, and (3) the hope of offering a better quality of life to patients.

Conclusions: The results of this study are preliminary in nature and cannot be generalized without a broader group of participants. However, the key factors identified provide a frame of reference to help understand the challenges of bioprinted cartilage and help facilitate the transition toward its clinical use. These findings will also provide information for use at multidisciplinary meetings in scientific societies; create bridges between researchers, orthopedic surgeons, and regulators; and open a debate on the funding of this technique and the business model that needs to be developed.
\end{abstract}

(JMIR Biomed Eng 2019;4(1):e12148) doi: 10.2196/12148

\section{KEYWORDS}

bioprinting; orthopedic surgeons; qualitative research; cartilage; expert testimony 


\section{Introduction}

\section{Background}

Traumatic cartilage lesions and arthritis are two of the most prevalent chronic diseases worldwide. According to data from the Global Burden of Disease Study [1], the number of people suffering from disorders caused by such diseases has increased from 140 million in 1990 to 242 million in 2013. Cartilage is a highly hydrated and specialized tissue providing a low-friction surface and resistance to erosion and diarthrodial joint load, allowing for effective articular movements. Unfortunately, the function and structure of cartilage are often damaged by trauma or ageing, adding to the fact that cartilage has a low capacity to self-heal.

Treatment of these diseases is still a challenge, and an effective solution remains to be found. These defects or lesions can last for years and can lead to arthritis [2]. Current repair techniques for cartilage lesions can be divided into two main groups: bone marrow stimulation and transplantation techniques $[3,4]$.

The potential of regenerative medicine and tissue engineering is now recognized worldwide. These new techniques are responsible for "shifting the paradigm in health care from symptomatic treatment in the 20th century to curative treatment in the 21st century" [5-7]. Currently, three-dimensional (3D) printing is used for several applications in the medical field, for example, in the printing of patient-specific osteotomy guides. Other surgical specialties use 3D printing to study the disease pathology in a patient and practice with a 3D-printed model before surgery [8].

Bioprinting refers to the use of $3 \mathrm{D}$ printing to combine cells, growth factors, and biomaterials to create tissues and organs mimicking the features of their natural counterparts [9]. Bioprinting generally uses the extrusion-based method, which consists of the layer-by-layer deposition of cells through bio-ink, creating a structure similar to the natural tissue that can be used in tissue engineering and medicine. Bioprinting, which emerged in 2004 with the use of additive manufacturing, combines cells, gels, and several biocompatible elements in a single scaffold, which can replace injured issue with a complex structure that contains several components, including structural and cellular constituents. The external shape and internal architecture can be modeled based on clinical images. Ideally, cartilage creations aimed to fill cartilage defects should be similar to the extracellular matrix to keep cells in their place and preserve a space for the tissue that will grow there [10]. Levato et al published that although the most suitable types of cells for bioprinting are well known, more research needs to be conducted regarding zonal organization of cartilage [11]. There is also the need to study the complex mechanical behavior of cartilage under compression, as a result of sliding and shear [12].

However, barriers and challenges for implementing a new technology must not be underestimated, and it is essential that they are addressed in advance to guarantee the widespread application of bioprinting once it has reached its maturity.
Research focused on this has been highlighted as crucial, since clinical efficiency and safety do not always lead to successful implementation. A recent editorial [13] encouraged implementation research at the beginning of development.

\section{Objectives}

This qualitative study aimed to explore the stance of orthopedic surgeons on the use of bioprinted cartilage grafts for cartilaginous lesions. We sought to classify the barriers and facilitators of this new technology and identify key factors that need to be considered for successfully implementation of bioprinted cartilage in routine clinical practice.

\section{Methods}

\section{Study Design}

The applied design consisted of a hybrid inductive and deductive thematic analysis, which allowed for interpreting gross data extracted from in-depth, semistructured interviews with orthopedic surgeons. This methodology was chosen to best reflect the perspective of interviewees.

\section{Inclusion Criteria}

For inclusion, orthopedic surgeons had to (1) have more than 5 years of experience in the field, (2) be currently working in a hospital, and (3) be actively performing surgery. No contacted participants were excluded.

\section{Ethical Compliance}

All participants were volunteers and agreed to participate in the interview or focus group. All were provided with the Ethics Research Committee document and signed the informed consent form. Authorization by the University Research Committee of University of Vic - Central of Catalonia (Spain) was granted (record number 28/2017).

All participants were informed in advance about the nature of the project, risks, advantages, and alternatives and their rights as research subjects. Measures were taken to ensure the data collected remained confidential; participants' safety and privacy were protected during and after the study.

\section{Participant Selection}

All participants were contacted via email, signed the informed consent form, and authorized the recording of the interview. Participants consisted of 18 orthopedic surgeons, ages 35-67. The group included 15 men and 3 women. Six were heads of units and 12 were specialists.

\section{Interview Structure for Data Generation}

In 2001, Patton [14] created a list of 6 question types that could be formulated based on behavior or experience, opinion or values, feelings, knowledge, and perception; those questions aimed to obtain demographic or background data. Our guideline included the following themes: 3D printing, bioprinted cartilage, cell origin, current needs, rejection, expectations, and suggestions. 
Figure 1. Flowchart of the interview process. IC: informed consent.

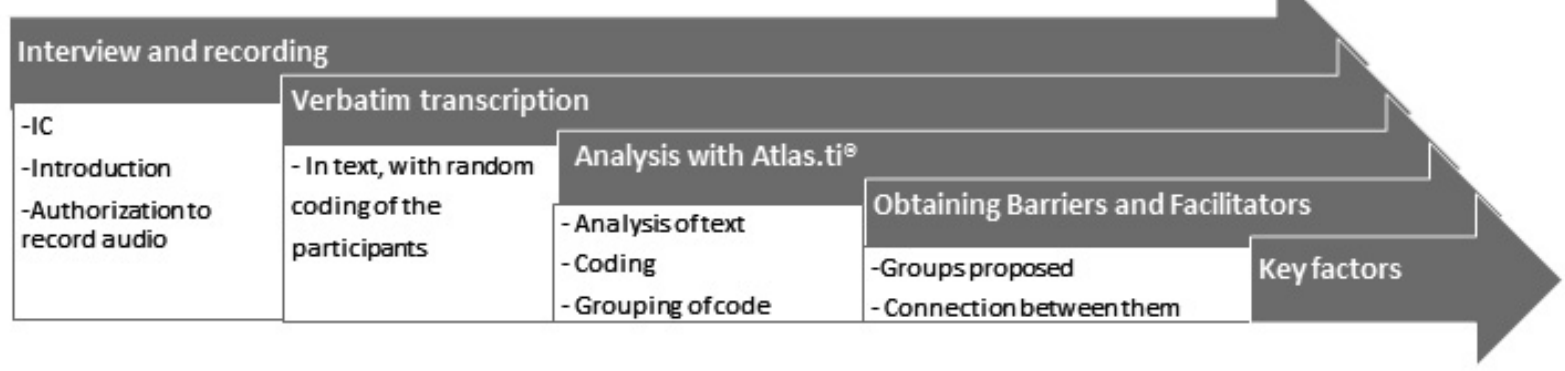

The interviews began by exploring the participants' knowledge regarding the medical applications of $3 \mathrm{D}$ printing and bioprinted cartilage. Questions on the use of stem cells were an important element of the interview, as much research is currently being conducted on mesenchymal cells obtained from umbilical cord tissue, adipose tissue, and bone marrow. The use of induced pluripotent stem (iPS) cells was also explored.

Questions related to current needs were aimed to corroborate the lack of efficiency in existing surgical techniques and the importance of research to find new practices. Questions on the expectations and reluctance of surgeons regarding the use of bioprinted cartilage sought to understand reasons for and against usage if the opportunity arose. The final section of the interview allowed for them to analyze the current situation and talk about future possibilities.

The interviews were always done with the same system (see the flowchart in Figure 1).

\section{Recording the Interviews}

The interviews and focus group discussions were conducted between June 2017 and February 2018. To protect the identity of all participants, each participant was codified to a randomly generated number that was then used in all study documentation. Their information was kept in a password-protected virtual folder of the university. Interviews were recorded digitally and transferred to the computer, where they were saved with the interviewee number and date of the recording. Informed consent forms were also stored at the university.

A single interview was conducted for each of the 18 participants, with the introduction providing context for the interview. The shortest and longest interviews were 25 minutes, 7 seconds and 43 minutes, 11 seconds, respectively. In total, we recorded 10 hours and 18 minutes of interviews.

Most interviews were conducted in the workplace of the interviewee, except for 4 participants who chose to have the interview in a coffee shop.

\section{Recording the Focus Groups}

Two focus groups were put together, and participant privacy was guaranteed in the same way as for the interviews. The first group consisted of 8 people, and the recording lasted 45 minutes,
23 seconds. The second group consisted of 5 people, and the recording lasted 74 minutes, 49 seconds.

\section{Global Data Analysis}

To ensure thematic integrity, this study used only data obtained from orthopedic surgeons. This analysis aimed to generate a list of relevant concepts that could be extrapolated and categorized. This leads to an inductive approach where topics have been identified by contextual information.

The integrity of the analysis was ensured by the directives established by Shenton [15], which included iterative questioning in data collection dialogues and the construction of an "audit trial," among others. The iterative process of grouping and subgrouping questions and answers led to a series of abstract constructions that were used to create a model to understand the context.

\section{Inductive and Deductive Analysis of the Data}

The analysis used mixed elements of inductive and deductive methods to interpret the gross data [16] and explore the attitude and experiences of the orthopedic surgeons interviewed. The flexibility of the approach helped analyze qualitative data from the interviews. The approach was useful in this study due to its large quantity of data.

Codification was reached through discussion and consent. Three researchers continued their discussion until consensus was reached regarding categorization and subcategorization of topics.

Braun and Clarke's [17] methodology, which identifies, analyzes, and describes reporting patterns, was used as a basis for thematic analysis. Due to the exploratory approach, this practical method was thought to fit the needs of the study perfectly. The process of thematic analysis is developed through 6 phases [18]. Phase 1 is becoming familiar with the data; Phase 2 is generating initial codes; Phase 3 is searching for themes and depuration of codes; Phase 4 is reviewing themes and finding those that are important either for reiteration or relevance to the research question; Phase 5 is defining and naming themes; and Phase 6 is producing the report.

Issues regarding trustworthiness were approached as described by Shenton [15], who provides a description of research, collection, and analysis design. The strategies used to ensure 
honesty in the interviews include encouragement to be candid and the assurance of the voluntary nature of the interview and the right to withdraw at any chosen moment. Transferability was accomplished by providing contextual in-depth information on the study and the role of the researcher. The researcher guaranteed confidentiality [19]. For data analysis and figure generation, ATLAS.ti version 8.2.34 was used.

\section{Results}

The analysis of the interviews and focus groups is presented in Table 1 with the aim of describing the current stance of orthopedic surgeons on cartilage grafting. The Table 1 list is what ATLAS.ti denominates as a "frequency count." It represents the number of times these concepts were identified in the texts. Each point was given a code denoting different levels of classification and abstraction, which were later linked to the established categories.

Within the discursive pattern of clinicians, two argumentative groups were identified, which were classified as facilitators and barriers. From these two groups of codes, the most relevant were selected to establish the key factors that will provide a general perspective on the stance of orthopedic surgeons.

\section{Barriers}

The barriers consist of the arguments and opinions put forward by the orthopedic surgeons that reflect the perceived challenges or the lack of information with regards to adopting the technology. Figure 2 shows the links between several components generated by ATLAS.ti. It shows the groupings and connections between the codes.

\section{Lack of Information}

The first barrier to be identified, which was coded as "lack of information," had an impact on the following aspects.

\section{Cell Therapy}

Orthopedic surgeons admitted their lack of knowledge regarding the acquisition and cell origin of chondrocytes. The participants showed great reluctance regarding the origin of the cells. Furthermore, if cell therapy implied the manipulation of unknown-origin cells, their stance was of total rejection. However, the level of acceptance was considerably higher if they knew the cells originated from the patient, even if they knew that they had to be manipulated (numbers in parentheses after quotes correspond to interviewee identity).

These constructors imply cell manipulation. [\#D 13]

We don't know if bone marrow or adipocyte is better, it seems like bone marrow could be useful, but it's not so clear. [\#23]

Table 1. Collected concepts and translation to numbers and codes.

\begin{tabular}{|c|c|}
\hline Concepts & $\mathrm{n}$ \\
\hline Need for clinical trials & 34 \\
\hline Implantation techniques & 28 \\
\hline Viability and traceability of the graft & 27 \\
\hline Characteristics of the cartilaginous tissue & 25 \\
\hline Small lesions (focal defects and osteochondritis) & 24 \\
\hline Durability & 14 \\
\hline Safety & 14 \\
\hline It's the future & 13 \\
\hline Costs & 13 \\
\hline Cell therapies & 12 \\
\hline Need to wait for clinical results & 12 \\
\hline Cell types & 12 \\
\hline Current techniques & 11 \\
\hline Uncertainty regarding the future & 10 \\
\hline Regulation & 10 \\
\hline Stem cells & 8 \\
\hline Technical difficulties in some articulations & 8 \\
\hline Cell viability & 8 \\
\hline Teratogenesis & 7 \\
\hline Biocompatibility & 7 \\
\hline
\end{tabular}


Figure 2. Diagram of the links between several study components.

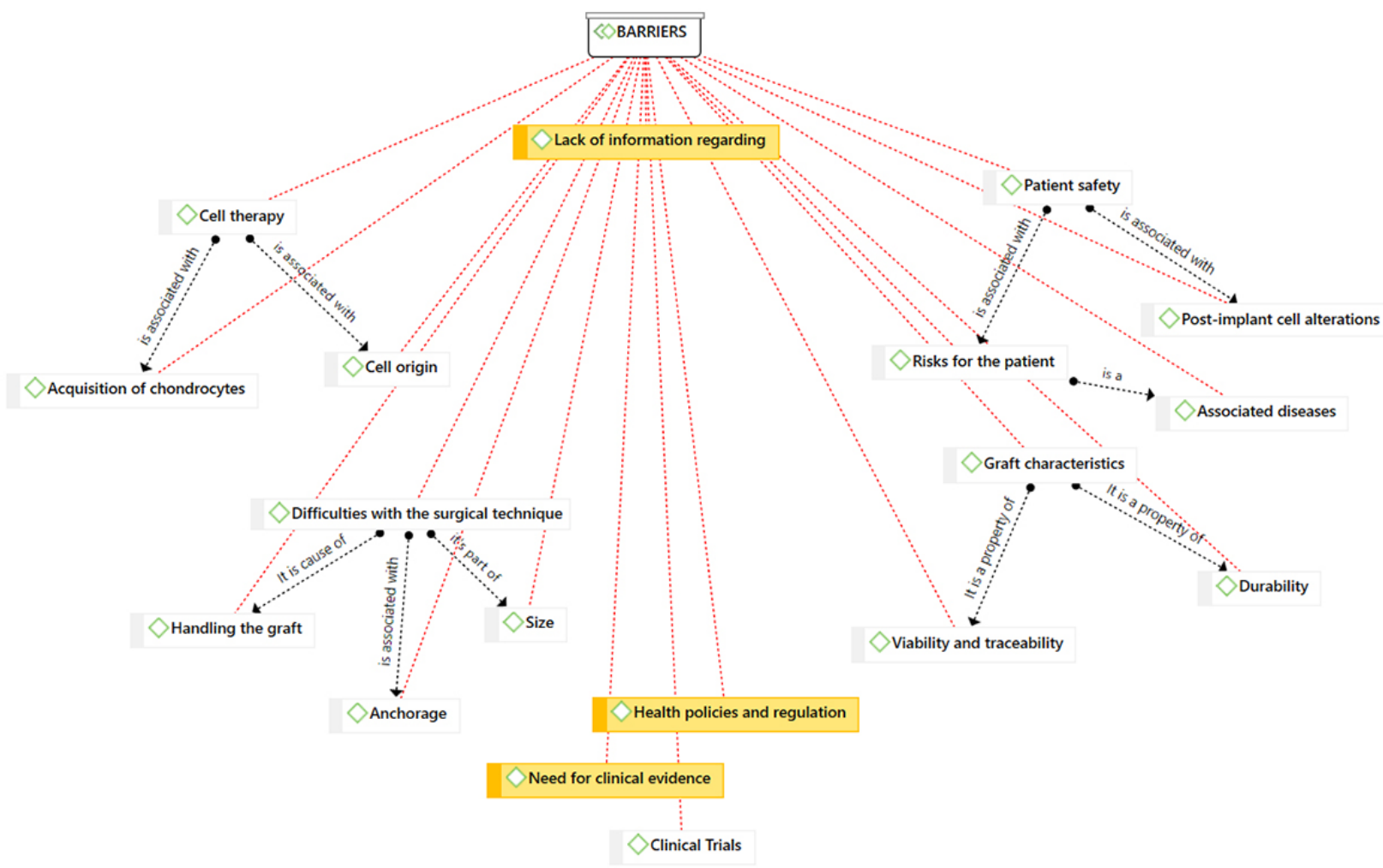

The better-known stem cell origins were mesenchymal, adipose, umbilical cord, and bone marrow as they are currently being used in other types of therapies.

I think mesenchymal cells are the way to go. [\#23]

There is a huge quantity of umbilical cord stored at the blood and tissue bank... Of umbilical cord cells, of adipose cells, cells of peripheral blood, from the skin; we can obtain cells from many places. [\#5181]

However, when trying to get the participants to discuss the topic in more detail, they appeared confused, especially when discussing iPS cells, which they were not aware of or did not fully understand.

The safety of iPS is not clear; there is an infinite number of complications-you can ask Yamanaka or Arnold Caplan. [\#23]

\section{Patient Safety}

All interviewees raised concerns regarding issues related to patient security, the graft, and associated diseases. With regards to the patient and the graft, the concerns focused on teratogenesis and the genetic predisposition of the cells in the graft, as well as the long-term behavior of the graft. Participants also showed a concern regarding graft implantation in patients with severe associated diseases, even though this fear does not have scientific merit.

Two types of safety: Safety for the patients' lives, of course, and safety in knowing that the graft will grow into cartilage, that you know for certain that this thing will create cartilage. [\#2341]

Three certainties: One, that these cells behave as we expect them to behave, like cartilaginous cells with no marginalization at all; two, that these cells are viable in the long term; and third, durability. If I am to implant cartilage, I'll want it to last. [\#204]

\section{Difficulties With the Surgical Technique}

Participants anticipated difficulties with regards to the shape of the graft, as they were unsure if the printing process could comply with the exact measurements provided by doctors. They also cited the place of injury as a possible difficulty.

Again, there's the problem of the three-dimensional structure of the cartilage. [\#2341]

Not all places are the same. For example, the knee: I think it's viable to insert it on the articular surface of the tibial plateau...Another thing is how it would anchor to the bone, right? But technically I don't see a difficulty here. Now then, it's another thing to insert it on the hip bone, between the cotyloid cavity and the femoral head. [\#6]

The lack of knowledge regarding the shape and manipulation of the graft, together with its characteristics led to a third kind of uncertainty, which we see as a barrier related to the surgical difficulties. Similarly, not being able to visualize the graft as part of cartilage that would adapt to the host left participants doubtful as to whether the graft would be able to anchor itself and stay in place.

Ideally, this graft would reproduce the defect exactly. [\#D 13]

I would use it now, for young people with osteochondritis of the talus or the knee, where you have a two- or three-millimeter. [\#5690] 
The size is a factor with the cartilage will it stay in place? [\#2901]

How will you fix it there? How? How does it stay there? [\#2341]

Another thing I worry about is that this tissue that we insert stays anchored. [\#6]

\section{Graft Characteristics}

Regarding graft characteristics, the main factors mentioned were viability, durability, integration with the host, and mechanical characteristics of cartilage. For example, participants doubted that the graft would become functional cartilage or develop chondrogenic hypertrophy, which is what happens with current techniques such as the matrix-induced autologous chondrocyte implantation (MACI) procedure.

Needs to have all the characteristics of the original cartilage. [\#6]

We need proof that long term there will still be cartilage and not fibrous tissue. [\#2901]

Needs to behave biologically like the host's cartilage. We're talking about live cells, right? [\#204]

Orthopedic surgeons also questioned the viability and durability of the graft. They were unaware that the aim of the graft is to become integrated to the native cartilage and that the graft's behavior would mimic the patient's native cartilage.

How long will it last? [\#6099]

And the viability of these cells, and their possible side effects. [\#1753]

Then, what I understand that these cells are viable themselves, it's not that they need to be invaded by the periphery, but that they are viable and live by themselves. [\#5181]

Figure 3. Diagram of the codes obtained as facilitators.

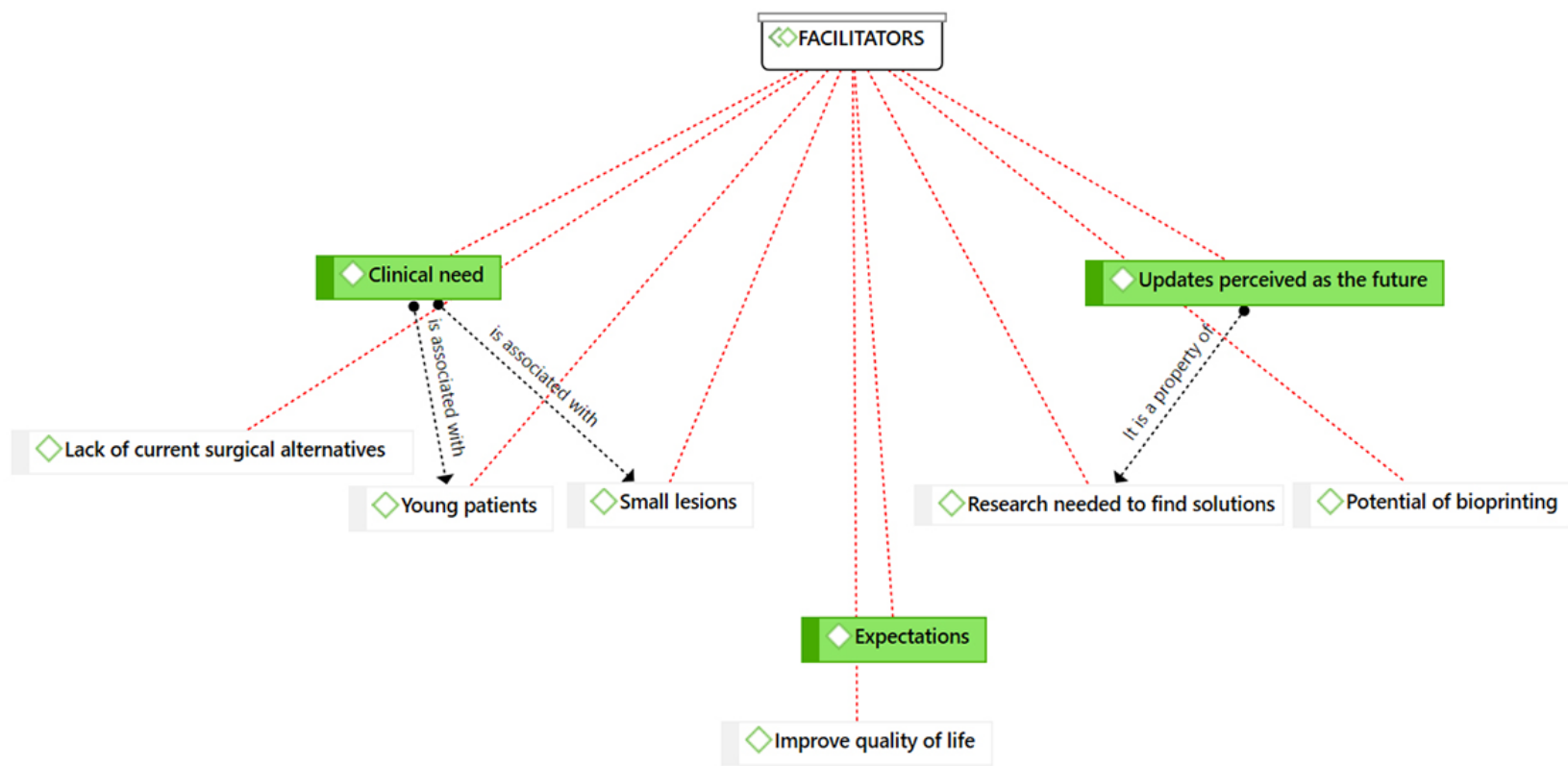

\section{Health Policies and Regulation}

Bioprinting, like any other product of tissue engineering will have to comply with the current Good Manufacturing Practice regulations enforced by the Food and Drug Administration and/or the European Medicines Agency.

The clinicians stated that they felt there would be a timeframe in which health policies will not be able to provide an effective answer to their questions, which would be problematic for all practitioners using them.

Who will guarantee the manufacturing process until its arrival in the operating room? [\#2083]

It's a legal aspect within the framework of drugs, implants, of techniques. We need to see this technique, legally the European guidelines on the use of tissues and cells. [\#4821]

\section{Need for Clinical Evidence}

As with any scientific innovation, orthopedic surgeons demanded hard clinical evidence be available before they would use bioprinted cartilage. In most cases, this demand materializes as clinical trials and independent clinical research. However, this may be a barrier since clinical trials are not scheduled to take place in the imminent future.

I want more evidence, that is to say, scientific studies that support their efficacy; independent scientific studies. [\#2901]

Basically, that there are appropriate clinical trials. [\#204]

\section{Facilitators}

Facilitators include all entities that encouraged orthopedic surgeons to be more open to new surgical possibilities to improve the lives of patients. In this group, three themes were identified that were essential to the clinicians to catalyze implementation of cartilage grafts (Figure 3). 


\section{Clinical Need}

Given that current surgical techniques are not able to provide a definitive solution, orthopedic surgeons are open to innovative techniques that can fill a surgical need. However, as they were not aware of the possibilities bioprinting would bring to field, most of the interviewees stated that research into finding new solutions was critical. Several arguments emphasize this need:

Especially as we don't have anything that works for these patients right now... if it lasts, say, 40 years, I'd say it's marvelous. [\#2901]

Nowadays this is something that doesn't have any solution, so of all the things I've heard about maybe this very innovative technique works since no other offer is effective. [\#2083]

If this works, it's very promising. [\#23]

In this way, the main facilitator identified was the lack of current alternatives, as was to be expected.

Taking this into consideration, orthopedic surgeons, despite the barriers mentioned, are open to this new technology.

We also identified the type of patients that surgeons would be willing to consider treating with bioprinted cartilage implementations. Younger patients were perceived to be better candidates, as they are susceptible to high-risk sports injuries, which often become chronic and difficult to solve in the long term.

That is, with young people with partial cartilage lesions, I see it very clearly; with bigger lesions, I am less optimistic [\#23]

I see it as a solution to young people's pathologies, athletes, that have damage due to chondral lesions and which can happen at any age, but they hinder young people's activity. [\#6]

Additionally, we identified the specific characteristic within this population that significantly improved the acceptance of bioprinting technology, namely the size of the lesion. Orthopedic surgeons were distinctly in favor of using grafts in small lesions ( 1 or $2 \mathrm{~cm}$ at most), in order to accelerate integration with the host. However, they did not show the same certainty with larger lesions.

I can see it being used with partial cartilage lesions. [\#2901]

If the lesions are small, and the joints are not loaded. [\#6356]

\section{Perception of Bioprinting as a Future Treatment}

Clinicians agreed that medicine depends on constant research to find solutions to unresolved problems. In other words, they perceived scientific research as a positive entity. Another argument identified the perception of bioprinting as a future solution, with participants being optimistic about graft bioprinting.
It is a future solution to important problems for orthopedic surgeons. [\#6346]
When we talk about the medicine of the future, which is not so far away now, to be able to reproduce the tissue of the patient. [\#204]

\section{Expectations}

Faced with an unresolved clinical need and the perception that bioprinting could be a solution in the future, orthopedic surgeons expect to hear about the benefits of this technique. Biocompatibility is not only a favorable factor but is essential to surgical practice. Many current techniques already have these characteristics, and therefore clinicians demand that future solutions meet or exceed these standards.

To find a three-dimensional structure that holds the cells, that holds what they must have, and that this three-dimensional structure is biocompatible, degradable, and easy to manipulate. [\#2341]

At the same time, participants emphasized that this technique had the ability to improve patients' quality of life significantly, either by alleviating their pain, improving their mobility, or by preventing lesions from developing into arthritis in younger patients. If these were to be accomplished with the new technology, surgeons expect the need for total prosthesis to diminish significantly.

\section{Key Factors}

Where barriers and facilitators meet, key factors emerge. Key factors function as the theoretical framework for the perspectives of orthopedic surgeons on bioprinted cartilage. In general, their belief is grounded on clinical need and expectations for effective solutions. Despite this, a reluctance to adopt the technology was detected among the interviewees, with reasons ranging from (conscious and unconscious) lack of information to clinical demands. Figure 4 offers a complex concept map, which is the first attempt to represent the stance of clinicians with an aim to help direct future research.

Apart from the elements present in both barriers and facilitators, two more factors were considered key factors and coded as such. They included costs and the identity of companies that would manage the product. It is impossible to address these uncertainties now; hence, they could not be labeled as either facilitators or barriers, only as relevant factors that need to be addressed. 
Figure 4. Where barriers and facilitators meet, key factors emerge.

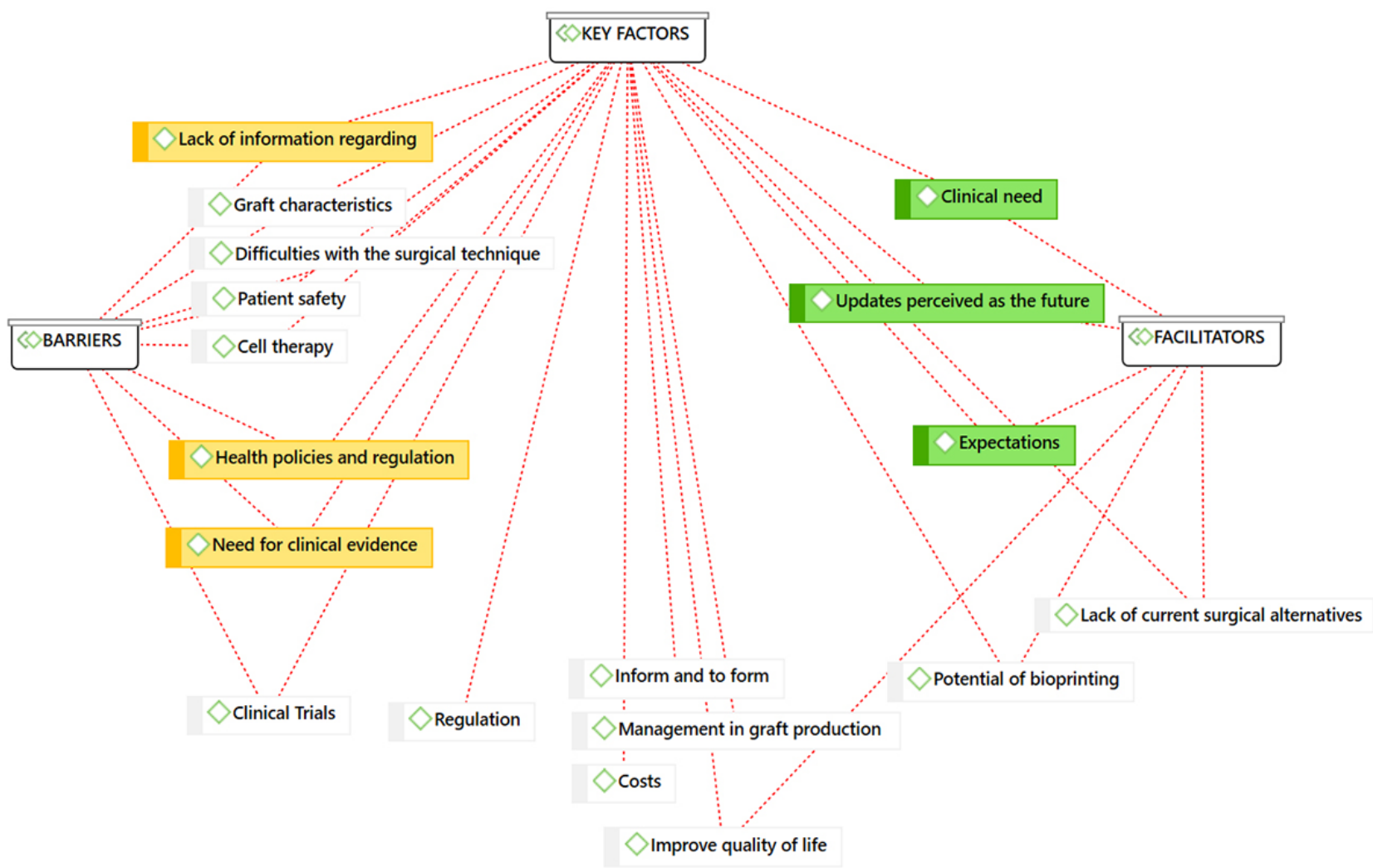

\section{Discussion}

\section{Principal Considerations}

As has been proven in a previous bibliographical review [20,21], the research and acquisition of bioprinted cartilage is still in a premature state. Other researchers have already highlighted that despite the growing number of solutions coming from tissue engineering that are being transitioned to clinical use, the success of considerably sized scaffoldings with personalized geometries is still a significant challenge. Therapies based on mesenchymal stem cells (MSC), despite having been successful in renovating the cartilage and alleviating pain, have not provided enough evidence on original hyaline cartilage restoration that would improve osteoarthritis in the long term.

The goal of this research is to understand how trauma surgeons perceive this situation and define main barriers and facilitators to develop strategies favoring the future implementation of bioprinted cartilage. The data collected and organized into either barriers or facilitators as detailed in our results will help future discussions focus on the most fundamental aspects of this technology.

One of the main needs identified is improving communication with orthopedic surgeons, particularly regarding 3D printing. The lack of knowledge was evident in two ways: conscious and unconscious. Of the two, the latter will be more difficult to address, as it requires further research to better identify the knowledge gaps. When conscious of their lack of knowledge, clinicians have no problem asking questions. However, the lack of knowledge was unconsciously displayed when assumptions were made regarding terms, techniques, or solutions leading to misinterpretation and confusion. To lead and conduct successful translational research, it is necessary to study and solve problems transversally. An unconscious deficit of knowledge was driven by reading publications or listening to conversations that dealt with cell therapy in a generic and unscientific manner. Thus, the lack of background knowledge was significant, resulting in misperceptions and unfounded reluctance in adopting the technology.

Furthermore, we discovered a lack of knowledge on current applications of 3D printing in medicine, with many of the interviewees having no knowledge of this facet. To address this issue, organization of specific multidisciplinary seminars to discuss the current applications of 3D printing in medicine should be undertaken. This could contribute to orthopedic surgeons becoming more proactive in the implementation of bioprinted cartilage grafts.

In parallel, efforts should be made to help promote an understanding of the fundamentals of cell therapy. This issue was identified as an unconscious knowledge gap. This was also observed in the case of gene therapy for cancer treatment [22]; participants were aware of the treatment but had no deep understanding of it. This was evident from the fact that they used cartilaginous cells provided by laboratories [23] but were reluctant to consider using bioprinted cartilage made of unknown-origin cells, or other cell therapies.

These findings highlight the evident need to develop formative strategies. These strategies would need to be based initially on the fundamentals of cell therapy, escalating toward the future possibilities this technology could offer. Thus, new channels of communication could be created in the medical community. 
While it is important for surgeons to have basic knowledge regarding the future applications of cartilage grafting, it is equally important for researchers to recognize and acknowledge the practical needs of clinicians and strive to meet their expectations. Some of the factors that caused the orthopedic surgeons concern included issues such as viability, traceability, and durability. Tissue and skin banks for allografts have established their reliability by ensuring traceability and establishing manipulation standards. Orthopedic surgeons now demand the same degree of reliability from bioprinted cartilage [24].

In addition to the characteristics of the graft, this study has identified important factors that would help direct research in the initial stages. First, by focusing research on specific lesions, such as 1 or $2 \mathrm{~cm}$ lesions found in the knee or the ankle, clinicians would have access to a site that is easier to access and operate on. Second, younger patients should be established as the primary recipients of the graft, with the aim of avoiding long-term joint deterioration.

Another issue detected during this study was concern regarding the business model for producing bioprinted grafts. Orthopedic surgeons feared it may not align with current production models. This situation, coded as a key factor, is one of the main issues identified as a barrier in the implementation of this technique.

By analyzing the stance of orthopedic surgeons, at least two possible lines of action can be suggested. If production was handled by private companies, the main demands from surgeons would be for the pieces to be individually customized, with a short production-delivery timeframe. In this instance, the biosafety and tissue traceability could be controlled. Another issue that would need addressing is the cost of the graft. This model would also need to address the patent issue and comply with the ethical requirements and, more importantly, with the current regulations and legislation. The Spanish company Regemat is an example of this. They use Hoffa's fat pad and chondrocytes as described by Lopez Ruiz [25] and induced differentiation of autologous MSC to develop and commercialize cartilage.

Another possibility would be to establish public centers, possibly in a public-private collaboration model, that would have the human and technical resources necessary to produce their own $3 \mathrm{D}$ bioprinted pieces. The foundations for such a model already exist in hospitals where 3D printers are already in use. As mentioned above, these hospitals have trained staff who are already competent in the use of 3D printers for a wide variety of uses ranging from the printing of fractures, surgical planning, and creating customized guides for the patient. This system, which would be integrated into hospitals, would allow for constant communication between the medical and technical teams. The hospital as a meeting point ensures that as the technology becomes widely used, more potential applications will be detected, thereby improving the learning curve for both sides - the medical team exploring new and better applications for the technique and the engineering team designing context-specific solutions. This solution would mean bioprinting is the next logical step, born from the growing needs of all medical specialties.

Cell therapy has stirred a debate within the scientific community. Cell therapy can be individually customized, is expensive and innovative, and might help bring a change in health regulation and health care policies. Our research has shown that the demands for scientific evidence for bioprinting will be more stringent than what was required for previous techniques. This is the case of platelet-rich plasma, which has been used by doctors for more than 20 years despite the lack of evidence for its effectiveness [26], with information on clinical trial outcomes having only recently been published [27].

Communication, not only among medical professionals, but among policy makers and health care authorities, is essential to start a debate to define the level and form of evidence required. In this manner, one of the main barriers highlighted by orthopedic surgeons, namely the need for clinical trials, could be surmounted.

\section{Limitations}

This study needs to be interpreted in the context of its limitations. There are inherent limitations to the number of participants and the number of focus groups. Only the data extracted from the orthopedic surgeons' interactions is legitimate; however, it is their opinion that focuses the research in this context.

\section{Conclusions}

These study results are preliminary in nature and therefore they cannot be generalized without a broader demographic. However, the preliminary literature review confirms the lack of research on clinical applications of bioprinted cartilage. Orthopedic surgeons are willing to accept that this new technology has the potential to solve a clinical need and to recognize bioprinting as the technology of the future. However, clear scientific evidence is required before bioprinted cartilage can be used and a debate regarding the optimal business model will be necessary.

We also believe it is necessary to develop a communication strategy and a forum for multidisciplinary discussion to discuss the need for regulation and define the necessary scientific evidence that is required to promote the acceptance of grafts as a viable therapeutic option. From our perspective, this study serves as a first step in the clinical translation of bioprinting cartilage research.

\section{Acknowledgments}

We would like to thank all participants in the interviews and focus group; Professor Juan Muñoz from the Social Psychology Department of the University Autonomy of Barcelona for his help with the methodology and the analysis; and Marina Mustieles for her help in the translation of this text. 


\section{Authors' Contributions}

The first author completed the field work and the analysis of the data obtained. The other authors contributed to the content, writing, and editing of the manuscript. All the authors read and approved the final version of the manuscript.

\section{Conflicts of Interest}

None declared.

\section{References}

1. Global Burden of Disease Study 2013 Collaborators. Global, regional, and national incidence, prevalence, and years lived with disability for 301 acute and chronic diseases and injuries in 188 countries, 1990-2013: a systematic analysis for the Global Burden of Disease Study 2013. Lancet 2015 Aug 22;386(9995):743-800 [FREE Full text] [doi: 10.1016/S0140-6736(15)60692-4] [Medline: 26063472]

2. O'Driscoll SW. The healing and regeneration of articular cartilage. J Bone Joint Surg Am 1998 Dec;80(12):1795-1812. [Medline: 9875939]

3. Maurer J, Grotejohann B, Jenkner C, Schneider C, Flury T, Tassoni A, et al. A Registry for Evaluation of Efficiency and Safety of Surgical Treatment of Cartilage Defects: The German Cartilage Registry (KnorpelRegister DGOU). JMIR Res Protoc 2016 Jun 29;5(2):e122 [FREE Full text] [doi: 10.2196/resprot.5895] [Medline: 27357998]

4. Gomoll AH, Farr J, Gillogly SD, Kercher JS, Minas T. Surgical management of articular cartilage defects of the knee. J Bone Joint Surg Am 2010 Oct 20;92(14):2470-2490. [Medline: 20962200]

5. Jessop ZM, Al-Sabah A, Francis WR, Whitaker IS. Transforming healthcare through regenerative medicine. BMC Med 2016 Dec 10;14(1):115 [FREE Full text] [doi: 10.1186/s12916-016-0669-4] [Medline: 27510095]

6. Jessop ZM, Javed M, Otto IA, Combellack EJ, Morgan S, Breugem CC, et al. Combining regenerative medicine strategies to provide durable reconstructive options: auricular cartilage tissue engineering. Stem Cell Res Ther 2016 Jan 28;7:19 [FREE Full text] [doi: 10.1186/s13287-015-0273-0] [Medline: 26822227]

7. O'Dowd A. Peers call for UK to harness "enormous" potential of regenerative medicine. BMJ 2013 Jul 01;347:f4248. [doi: 10.1136/bmj.f4248] [Medline: 23818565]

8. Bizzotto N, Tami I, Santucci A, Adani R, Poggi P, Romani D, et al. 3D Printed replica of articular fractures for surgical planning and patient consent: a two years multi-centric experience. 3D Print Med 2015;2(1):2 [FREE Full text] [doi: 10.1186/s41205-016-0006-8] [Medline: 30050974]

9. Gu BK, Choi DJ, Park SJ, Kim MS, Kang CM, Kim CH. 3-dimensional bioprinting for tissue engineering applications. Biomater Res 2016;20:12 [FREE Full text] [doi: 10.1186/s40824-016-0058-2] [Medline: 27114828]

10. Chen JL, Duan L, Zhu W, Xiong J, Wang D. Extracellular matrix production in vitro in cartilage tissue engineering. J Transl Med 2014 Apr 05;12:88 [FREE Full text] [doi: 10.1186/1479-5876-12-88] [Medline: 24708713]

11. Levato R, Visser J, Planell J, Engel E, Malda J, Mateos-Timoneda M. Biofabrication of tissue constructs by 3D bioprinting of cell-laden microcarriers. Biofabrication 2014 Sep;6(3):035020. [doi: 10.1088/1758-5082/6/3/035020] [Medline: 25048797]

12. Mohan Pandey P, Venkata Reddy N, Dhande S. Slicing procedures in layered manufacturing: a review. Rapid Prototyping Journal 2003 Dec;9(5):274-288 [FREE Full text] [doi: 10.1108/13552540310502185]

13. Peters DH, Adam T, Alonge O, Agyepong IA, Tran N. Implementation research: what it is and how to do it. BMJ 2013 Nov 20;347:f6753. [doi: 10.1136/bmj.f6753] [Medline: 24259324]

14. Patton MQ. Qualitative Research \& Evaluation Methods. 3rd ed. Thousand Oaks, CA: Sage Publications, Inc; 2001.

15. Shenton A. Strategies for ensuring trustworthiness in qualitative research projects. EFI 2004 Jul 19;22(2):63-75. [doi: 10.3233/EFI-2004-22201]

16. Fereday J, Muir-Cochrane E. Demonstrating Rigor Using Thematic Analysis: A Hybrid Approach of Inductive and Deductive Coding and Theme Development. International Journal of Qualitative Methods 2016 Nov 29;5(1):80-92 [FREE Full text] [doi: 10.1177/160940690600500107]

17. Braun V, Clarke V. Using thematic analysis in psychology. Qualitative Research in Psychology 2006 Jan;3(2):77-101. [doi: 10.1191/1478088706qp063oa]

18. Carroll E, Coetzer R. Identity, grief and self-awareness after traumatic brain injury. Neuropsychol Rehabil 2011 Jun;21(3):289-305. [doi: 10.1080/09602011.2011.555972] [Medline: 21391119]

19. Malterud K. Qualitative research: standards, challenges, and guidelines. Lancet 2001 Aug 11;358(9280):483-488. [doi: 10.1016/S0140-6736(01)05627-6] [Medline: 11513933]

20. Roseti L, Cavallo C, Desando G, Parisi V, Petretta M, Bartolotti I, et al. Three-Dimensional Bioprinting of Cartilage by the Use of Stem Cells: A Strategy to Improve Regeneration. Materials (Basel) 2018 Sep 17;11(9) [FREE Full text] [doi: 10.3390/ma11091749] [Medline: $\underline{30227656]}$

21. Xiongfa J, Hao Z, Liming Z, Jun X. Recent advances in 3D bioprinting for the regeneration of functional cartilage. Regen Med 2018 Dec;13(1):73-87. [doi: 10.2217/rme-2017-0106] [Medline: 29350587]

22. Wirth T, Ylä-Herttuala S. Gene Therapy Used in Cancer Treatment. Biomedicines 2014 Apr 08;2(2):149-162 [ㅍREE Full text] [doi: 10.3390/biomedicines2020149] [Medline: 28548065] 
23. Guillén-García P, Rodríguez-Iñigo E, Aráuz S, Guillén-Vicente M, Guillén-Vicente I, Caballero-Santos R, et al. Nuestra experiencia con la técnica de implante de condrocitos autólogos para el tratamiento de lesiones condrales: resultados de 50 pacientes a 2 años de seguimiento. Revista Española de Artroscopia y Cirugía Articular 2015 Dec;22(3):120-125 [FREE Full text] [doi: 10.1016/j.reaca.2015.10.002]

24. Martínez-Flores F, Sandoval-Zamora H, Machuca-Rodriguez C, Barrera-López A, García-Cavazos R,

Madinaveitia-Villanueva J. [Skin and tissue bank: Operational model for the recovery and preservation of tissues and skin allografts]. Cir Cir 2016;84(1):85-92 [FREE Full text] [doi: 10.1016/j.circir.2015.06.021] [Medline: 26259741]

25. López-Ruiz E, Perán M, Cobo-Molinos J, Jiménez G, Picón M, Bustamante M, et al. Chondrocytes extract from patients with osteoarthritis induces chondrogenesis in infrapatellar fat pad-derived stem cells. Osteoarthritis Cartilage 2013 Jan;21(1):246-258 [FREE Full text] [doi: 10.1016/j.joca.2012.10.007] [Medline: 23085560]

26. Anitua E. Plasma rich in growth factors: preliminary results of use in the preparation of future sites for implants. Int J Oral Maxillofac Implants 1999;14(4):529-535. [Medline: 10453668]

27. Gamal AY, Abdel Ghaffar KA, Alghezwy OA. Crevicular Fluid Growth Factors Release Profile Following the Use of Platelet-Rich Fibrin and Plasma Rich Growth Factors in Treating Periodontal Intrabony Defects: A Randomized Clinical Trial. J Periodontol 2016 Dec;87(6):654-662. [doi: 10.1902/jop.2016.150314] [Medline: 26876351]

\title{
Abbreviations \\ iPS: induced pluripotent stem \\ MSC: mesenchymal stem cells
}

\author{
Edited by $G$ Eysenbach; submitted 08.09.18; peer-reviewed by V Giordano, P Haubruck, $M$ Soto, C Basch; comments to author \\ 30.01.19; revised version received 11.02.19; accepted 17.02.19; published 28.02.19 \\ Please cite as: \\ Salvador Verges À, Fernández-Luque L, Yildirim M, Salvador-Mata B, Garcia Cuyàs F \\ Perspectives of Orthopedic Surgeons on the Clinical Use of Bioprinted Cartilage: Qualitative Study \\ JMIR Biomed Eng 2019;4(1):e12148 \\ URL: http://biomedeng.jmir.org/2019/1/e12148/ \\ doi: $10.2196 / 12148$ \\ PMID:
}

(C)Àngels Salvador Verges, Luis Fernández-Luque, Meltem Yildirim, Bertran Salvador-Mata, Francesc Garcia Cuyàs. Originally published in JMIR Biomedical Engineering (http://biomedeng.jmir.org), 28.02.2019. This is an open-access article distributed under the terms of the Creative Commons Attribution License (https://creativecommons.org/licenses/by/4.0/), which permits unrestricted use, distribution, and reproduction in any medium, provided the original work, first published in JMIR Biomedical Engineering, is properly cited. The complete bibliographic information, a link to the original publication on http://biomedeng.jmir.org/, as well as this copyright and license information must be included. 